\title{
A FILOSOFIA COMO CAMINHO PARA A FÉ CRISTÃ SEGUNDO JUSTINO DE ROMA
}

\author{
PHILOSOPHY AS A WAY TO CHRISTIAN FAITH ACCORDING TO JUSTINE OF ROME \\ Felipe Barrozo Arboith
}

\section{RESUMO}

O presente escrito visa embrenhar-se nos estudos do pensamento do filósofo cristão Justino, para buscar ideias e argumentos visando a justificação da ligação entre filosofia e a doutrina cristã. Quer-se, com isso, entender a necessidade que há de, antes de adentrarmos nos estudos teológicos, aprofundarmo-nos nas teorias filosóficas principalmente dos pensadores antigos. Além disso, visa-se encontrar razões para acreditar na possível complementaridade entre filosofia e teologia. Assim, com o auxílio de Justino, filósofo e mártir cristão, conseguiremos resolver o impasse que há no entendimento da necessidade que se coloca do estudo filosófico antes do aprofundamento teológico, dentro das razões cristãs de se explicar a fé.

Palavras-chave: Filosofia. Teologia. Cristianismo. Patrística.

\begin{abstract}
The present writing aims to engage in the studies of thought of the Christian philosopher Justino, to seek ideas and arguments aimed at justifying the link between philosophy and Christian doctrine. With this, we want to understand the need there is, before entering into theological studies, to delve into philosophical theories - mainly from ancient thinkers. In addition, the aim is to find reasons to believe in the possible complementarity between philosophy and theology. Thus, with the help of Justin, a philosopher and a Christian martyr, we will resolve the impasse that exists in the understanding of the need that arises from the philosophical study before theological approach, within Christian reasons for explaining the faith.
\end{abstract}

Keywords: Philosophy. Theology. Christianity. Patristics.

1 Licenciado em Filosofia pela Faculdade Palotina de Santa Maria-RS. Professor de Filosofia da rede pública do Estado de Santa Catarina. E-mail: fba.333@bol.com.br 


\section{INTRODUÇÃO}

Tanto nas casas de formação para o sacerdócio, como em qualquer curso de teologia, sempre nos é apresentado, como um dos pré-requisitos, um aprofundamento nas afirmações e teorias filosóficas. A questão da indispensabilidade da filosofia no estudo teológico sempre é enfatizada.

Muitas vezes, se confirma isso baseando-se na necessidade do desenvolvimento argumentativo e no entendimento de diversos termos filosóficos utilizados também nos estudos da teologia. Mas isso nos parece muito superficial. Sempre há sinais de que existe uma explicação mais intrínseca da necessidade da filosofia para se aprofundar nas ciências teológicas. É muito comum o estudante se deparar com o problema da justificação da filosofia como base para a teologia.

Ao vasculharmos tanto a história do cristianismo, como a história da própria filosofia, vemos que muitos pensadores também se depararam com esse mesmo problema. A justificação da filosofia permeou escritos e pensamentos de teólogos e filósofos cristãos durante toda história, principalmente nos períodos iniciais do cristianismo, com ênfase nas obras dos chamados "Padres da Igreja".

Nesses períodos iniciais do pensamento cristão nos deparamos com Justino, filósofo a mártir cristão, que na totalidade de sua obra, ou naquilo que temos acesso hoje, tratou acerca desse problema. De origem pagã, durante a primeira parte de sua vida, passou por inúmeras escolas filosóficas de seu tempo, em busca daquilo que ele chama de "verdade". Após sua conversão ao cristianismo, se preocupou em justificar a ligação que há da filosofia antiga com a doutrina cristã, abraçada por ele, sem deixar de ser filósofo.

Assim, podemos deduzir que, ao aprofundarmos nosso estudo nos escritos de Justino, poderemos ter algumas respostas para as questões que levantamos inicialmente. Se esse filósofo passou pelas inquietações que os estudantes de teologia passam, ao defrontar-se com a necessidade de se estudar filosofia para depois embrear-se nas discussões teológicas, podemos daqui tirar respostas para clarear essa questão.

Queremos analisar as afirmações de Justino, filósofo e mártir cristão dos primeiros séculos, ao tratar da justificação da filosofia e sua ligação com a doutrina cristã. Visamos, da argumentação e explanação do filósofo, garimpar para nós, ideias e luzes para compreendermos como, do ponto de vista teológico, há essa necessidade do trabalho filosófico para compreender-se, ou seja, a necessidade da fé em contar com o auxílio da razão para auto entender-se, chegando assim ao cerne da complementaridade dessas duas áreas do conhecimento humano.

Que tenhamos sucesso nessa empreitada.

\section{O CAMINHO PERCORRIDO DO PAGANISMO À VERDADEIRA FILOSOFIA}

\section{A DESILUSÃO COM A FILOSOFIA GREGA}

Justino, filósofo e mártir, um dos apologetas mais antigos do cristianismo², ao converter-se do paganismo não abandona a filosofia, mas defende a ideia de que ela é o caminho seguro para conquistarmos a contemplação do divino.

2 Mais detalhes biográficos e explanação acerca dos apologetas dos primeiros séculos, ver FIGUEIREDO, 2009 , p. 61. 
"Para Justino, a filosofia é aquilo que nos conduz a Deus e nos une a Ele. A dificuldade, porém, estava em escolher uma dentre as muitas filosofias que se lhe defrontavam". ${ }^{3}$

Para o filósofo, a filosofia como a busca pela verdade por excelência, se mostra como um dos principais caminhos para se conquistar a contemplação de Deus, o qual é a verdade perfeita. Afirmando isso, em meio à diversidade de caminhos existentes dentro da própria filosofia, desenvolve sua análise se perguntando qual desses é o mais seguro para se chegar a suma verdade, Deus.

São Justino, como é conhecido no universo cristão, fora pagão e, já na sua vida adulta, converte-se ao cristianismo. Na sua juventude, passa por várias correntes filosóficas, tais como os pensamentos estóico, peripatético e pitagórico ${ }^{4}$. Se desilude com todas essas e volta-se finalmente para a filosofia platônica, onde permanece por grande parte de sua vida. Assim, entusiasma-se pela especulação platônica e principalmente pela doutrina da existência da realidades incorpóreas, as ideias ${ }^{56}$.

Para o pensador, era certo que logo comtemplaria Deus, fim último da filosofia de Platão7. Para alcançar isso, Justino passa a viver isolado, em um lugar ermo, à beira mar. Buscava entregar-se à contemplação e meditação ${ }^{8}$.

Nesse lugar, segundo narrativa do próprio filósofo, ocorre um fato que mudará completamente sua vida. Num determinado dia, encontra-se com um ancião e o mesmo lhe questiona sobre os motivos que Ihe trazem a viver ali. "Justino respondeu que viera àquele lugar para cultivar a filosofia, da qual Ihe adviria a felicidade" ${ }^{\prime}$. Com isso, o ancião o impeliu sobre seu entendimento acerca da filosofia e da felicidade. A filosofia, respondeu Justino, "é a ciência do ser e do conhecimento da verdade, e felicidade é a recompensa dessa ciência e desse conhecimento"10.

O ancião continua o diálogo perguntando a Justino o que ele entende por "Deus". O filósofo diz que "Deus é aquele que é sempre encontrado do mesmo modo. Ele é invariável e também a causa do ser de todos os outros seres"11. Essa afirmação já nos mostra que seu pensamento já se distanciava daquilo que os pagãos defendiam em seu politeísmo. Tanto é que, "o ancião cristão, que continua a dirigir o diálogo, nada tem a objetar contra a definição"12. Seus questionamentos estão direcionadas às bases internas desse conhecimento, e não ao próprio.

3 BOEHNER; GILSON, 2012, p. 27.

4 Cf. FIGUEIREDO, 2009, p. 61.

5 Cf. BOEHNER; GILSON, 2012, p. 27.

6 Pode-se ainda ver a própria narrativa do filósofo em sua obra "Diálogo com Trifão".

7 "A contemplação das ideias dava asas à minha inteligência. Eu imaginava ter-me tornado sábio num átimo, e minha estupidez fazia-me esperar que, de um momento para outro, contemplaria o próprio Deus. Com efeito, esta é a meta da filosofia de Platão", dito pelo próprio Justino em "Diálogo com Trifão, 2,6", In. Patrística Vol.3 p. 79.

8 Cf. BOEHNER; GILSON, 2012, p. 27.

$9 \mathrm{Cf}$. Ibidem.

10 JUSTINO, Diálogo com Trifão 3,4. In. Patrística Vol.3 p. 80.

11 Ibid. 3,5. In. Patrística Vol.3 p. 80

12 Cf. BOEHNER; GILSON, 2012, p. 27. 
O ancião, perante essas afirmações, continua questionando o pensador tentando fazer florescer aquilo que provavelmente já existisse em seu interior: "Então como os filósofos entendem ou falam corretamente sobre Deus se não têm ciência dele, pois não o viram, nem jamais o ouviram?"13.

Justino responde essa última indagação dizendo que, segundo Platão, temos um olho espiritual que nos capacita a contemplar, em si mesmo, aquele ser que é a causa de todas as coisas sensíveis ${ }^{14}$, e ainda, afirma que existe um parentesco entre a alma e Deus. E que, para o homem conseguir chegar a essa contemplação, é necessário trilhar um caminho de purificação, vivendo posteriormente uma vida virtuosa ${ }^{15}$.

O ancião, por sua vez, refuta a ideia de que a alma possua parentesco com Deus, provando que não há nada de divino nela e, muito menos, que é formada por uma parte divina. Prova a incoerência dessa afirmação e mostra que a alma, assim como o mundo e o corpo, tem um início em sua existência e que não são imortais, como é Deus ${ }^{16}$.

Justino, então, é forçado a admitir que seus mestres eram incapazes de conduzi-lo à verdade e pergunta-se: "Então a quem vamos tomar como mestre ou de quem poderemos tirar algum proveito, se nem mesmo nestes se encontra a verdade?"17. Assim, Justino se desilude com a filosofia grega e parte em busca da verdadeira filosofia ${ }^{18}$.

\title{
CRISTIANISMO, A VERDADEIRA FILOSOFIA
}

A partir da certeza de que a alma não pode obter a visão de Deus, enquanto permanecer no domínio meramente natural, acaba aceitando a religião que, não só promete conduzi-lo a Deus, mas que também Ihe proporciona os meios de conseguir isso. "O cristianismo cumpre as promessas da filosofia, e por isso ele é a verdadeira filosofia"19.

Justino diz:

\begin{abstract}
"Ditas essas coisas e muitas outras, que não é o caso de referir agora, o velho foi embora, depois de exortar-me a seguir os seus conselhos. E eu não voltei a vê-lo mais. Contudo, senti imediatamente que se acendia um fogo em minha alma e se apoderava de mim o amor pelos profetas e por aqueles homens amigos de Cristo. Refletindo comigo mesmo sobre os raciocínios do ancião, cheguei à conclusão de que somente essa é a filosofia segura e proveitosa"20.
\end{abstract}

13 JUSTINO, Diálogo com Trifão 3,7. In. Patrística Vol.3 p. 81.

14 Resposta de Justino: "Platão, de fato, afirma que assim é o olho da inteligência, e que ela nos foi dada exatamente para contemplar com ele, por ser olho puro e simples, aquele mesmo que é causa de tudo o que é inteligível, sem ar, sem forma, sem tamanho, sem nada daquilo que o olho vê, mas que é o próprio ser, indizível e inexplicável, além de toda a essência, o único belo e bom que aparece imediatamente nas almas de excelente natureza, por aquilo que tem de semelhante a ele e por seu desejo de contemplá-lo", Diálogo com Trifão, 4,1. In. Patrística Vol.3. p. 81.

15 Cf. JUSTINO, Diálogo com Trifão 4,2-3. In. Patrística Vol.3 p. 81.

16 Cf. Ibid. 5,1-5 e 6,1. In. Patrística Vol.3 p. 83-84.

17 Cf. Ibid. 7,1. In. Patrística Vol.3 p. 84.

18 Cf. BOEHNER; GILSON, 2012, p. 27.

19 Ibid. p. 28.

20 JUSTINO, Diálogo com Trifão 8,1. In. Patrística Vol.3 p. 85. 
O cristianismo nos leva a contemplar Deus, o qual é a suma verdade, realidade final da busca filosófica. Se Deus é a verdade, e o saber filosófico tem como meta alcançar a verdade de todas as coisas, o cristianismo, como aminho seguro para se chegar a Deus, se confirma como a verdadeira filosofia.

Outra realidade que confirma essa certeza é a finalidade última tanto do cristianismo, como da filosofia. O primeiro nos leva a contemplar Deus para que, no fim alcancemos a verdadeira felicidade. Já a filosofia também nos leva a buscar a verdade para que sejamos felizes. Deus, sendo a verdade suprema, também é a fonte por excelência da felicidade plena e absoluta. Assim, Justino conclui que a verdadeira filosofia é o cristianismo, caminho seguro para a contemplação da verdade e para a conquista da felicidade plena.

Após chegar nessa conclusão, São Justino, ainda no diálogo com o ancião misterioso, manifesta o desejo de saber onde se encontra o verdadeiro caminho que o levará a Deus. O interlocutor the indica as Sagradas Escrituras, as quais, segundo o mesmo, foram escritas por homens inspirados pelo Espírito Santo, que contemplaram a verdade e anunciam-na sem temor e sem ambições terrenas, sendo testemunhas oculares da verdade e, por isso, exigem fé, visto que não trazem argumentos ${ }^{21}$.

O ancião ainda firma à Justino que, o meio para se chegar a contemplação da verdade necessita de muita oração, para que a luz da verdade se abra. Disse o ancião:

"Quanto a ti, antes de tudo, roga que as portas da luz te sejam abertas, pois estas coisas nem todos as podem ver e compreender, a não ser aqueles a quem Deus e seu Cristo concedem o dom de compreender"22.

Ensina que, só consegue chegar a essa contemplação, àquele que Deus e seu Cristo conferir a inteligência necessária. Justino, então, se apaixona pelo cristianismo, se torna cristão e diz que é assim que se transformou em um verdadeiro filósofo, contemplando a verdade suprema que é Deus ${ }^{23}$.

Conclui Justino:

\footnotetext{
"Desse modo, portanto, e por esses motivos, sou filósofo, e desejaria que todos os homens, com o mesmo empenho que eu, seguissem as doutrinas do Salvador. Com efeito, nelas há alguma coisa de temível e são capazes de comover os que se afastam do caminho reto, ao mesmo tempo que elas se convertem em dulcíssimo descanso para aqueles que nelas meditam"24.
}

\section{A REFUNDAÇÃO DO CONCEITO DE FILOSOFIA}

Na conversão de São Justino podemos perceber claramente uma transformação completa do que se entende por filosofia. Esse entendimento passa das mãos dos gregos para a dos cristãos, trazendo uma nova compreensão do que se entende acerca da busca filosófica pela verdade.

21 Cf. BOEHNER; GILSON, 2012, p. 28.

22 JUSTINO, Diálogo com Trifão 7,2. In. Patrística Vol.3 p. 85

23 Cf. BOEHNER; GILSON, 2012, p. 28.

24 JUSTINO, Diálogo com Trifão 8,2. In. Patrística Vol.3 p. 85 
Para o filósofo, os problemas levantados pela sabedoria grega são os mesmos respondidos pelo cristianismo. Tanto os filósofos gregos antigos como os cristãos buscam a Deus e aspiram à união da alma com Ele.

A filosofia grega, ao buscar um objetivo religioso, cria para si um problema irresolvível, que está além das forças da razão humana. Para isso Justino afirma poder existir duas soluções: ou fica somente ligada a um objetivo que lhe é acessível, o qual não poderá ser de natureza religiosa, ou seu objetivo se transforma em uma realidade propriamente religiosa e, nesse caso, deverá transcender a filosofia natural adotando a religião cristã, a qual tomará, assim, o nome de "Filosofia"25.

Para Justino, isso prova que o cristianismo é a verdadeira filosofia e que, pela conversão, ele se tornou um verdadeiro filósofo. Isso se dá pelo fato de que é a fé cristã que permite a razão alcançar as verdades mais imprescindíveis. Além disso, as verdades cristãs nos trazem a graça divina, tornando-se, não só a filosofia plena, mas também caminho de salvação, graças às mudanças que incute na vida daqueles que nelas se aprofundam.

\section{A PRESENÇA DO LOGOS NA FILOSOFIA GREGA}

\section{O PROBLEMA DA FILOSOFIA ANTERIOR A CRISTO}

A afirmação de São Justino de que o cristianismo é a verdadeira filosofia, Ihe trouxe alguns problemas não evitados pelo pensador: se o cristianismo é a verdadeira filosofia, o que dizer dos filósofos anteriores à Cristo? Iremos condená-los por não terem contato ou ignorado a revelação?

Como resposta a essa indagação o filósofo lembra que foram os mestres gregos que o haviam trazido às proximidades do cristianismo e assim defende que os mesmos merecem sim lugar na religião de Cristo, visto que tiveram uma certa participação no "verbo"26.

Justino ensina que toda verdade está no logos (Verbo), que é a verdade suprema de Deus. Esse logos ilumina todo homem que vem a este mundo, "Pois Ele é o Verbo, que está em todo homem"27.

Em sua segunda apologia, Justino ao falar dos estóicos, que foram odiados e mortos, afirma que esses, assim como os poetas, se mostravam moderados na vida ética, pois continham em si "a semente do Verbo, que se encontra ingênita em todo o gênero humano"28. Para ele, em todo homem de boa vontade, ou de boa índole, justo e ético, está a "semente do Verbo", intrínseca na raça humana.

Assim, toda verdade deve ser relacionada ao Logos. Na filosofia grega se conhecera e se praticara a verdade. Por isso, no pensamento grego estava presente, mesmo que de forma imperfeita e fragmentada, o Logos, ou seja, a verdade do Verbo revelado em Cristo $^{29}$.

25 Cf. BOEHNER; GILSON, 2012, p. 28.

26 Cf. Ibid. p. 29.

27 JUSTINO, Apologia II, 10,8. In. Patrística 3, p. 71.

28 Ibid. 7,1. In. Patrística 3, p. 69.

29 Cf. Ibid. 10,1-8. In. Patrística 3, p. 70-71. 


\section{A participação dos filósofos no Logos}

São Justino afirma que os filósofos antigos, como Platão e os estóicos, conheceram e praticaram a verdade, por isso tiveram parte no Logos, mas não o possuíram de forma integral. O logos total encontramos em Cristo, mas naqueles filósofos somente em parte ou inicialmente ${ }^{30}$.

Ele afirma em sua segunda apologia: "Com efeito, tudo o que os filósofos e legisladores disseram e encontraram de bom, foi elaborado por eles pela investigação e intuição, conforme a parte do Verbo que lhes coube" ${ }^{\prime 1}$. Ou seja, tudo aquilo que os homens anteriores a Cristo fizeram de acertado, de bom, de ético e verdadeiro, só foi feito assim por causa do Verbo que está em todo homem. Esses, viveram conforme os sinais do Verbo intrínseco a si.

"Ao número destes filósofos pertencem Sócrates, Platão e os estóicos, pelos quais Justino tem sincera admiração; mas nem por isso exclui de sua companhia os poetas, os legisladores e os historiadores. No que respeita a Platão, é manifesto que Justino desejaria dar mais um passo, pois sente-se na obrigação de explicar por que este pensador é, a bem dizer, um cristão, e não um platônico"32.

São Justino inclui no âmbito dos "cristãos antes de Cristo" todo homem que viveu conforme a verdade. Nisso, inclui várias classes de pensadores, além dos filósofos a que ele admirava, por ter anteriormente participado de escolas que seguiam seus ensinamentos. Vê-se porém uma nítida preferência, ou uma ênfase maior, em tratar sobre Platão, o qual chega a afirmar que esse era muito mais cristão do que propriamente platônico.

Além disso, diz que mesmo que não haja uma diferença expressiva entre a doutrina platônica e a cristã, nenhum deles, nem Platão e nenhum dos demais filósofos, podem ser julgados como rivais à Cristo. Pois, "tudo o que de bom foi dito por eles, pertence a nós, cristãos, porque nós adoramos e amamos, depois de Deus, o Verbo, que procede do mesmo Deus ingênito e inefável”33.

Para Justino, os filósofos antigos participaram do Logos, visto que todos os seus conhecimentos e descobertas só foram possíveis por terem parte no mesmo. Porém, não possuíram o logos total34.

o filósofo afirmou:

"De fato, cada um falou bem, vendo o que tinha afinidade com ele, pela parte que lhe coube do Verbo seminal divino. Todavia, é evidente que aqueles que em pontos muito fundamentais se contradisseram uns aos outros, não alcançaram uma ciência infalível, nem um conhecimento irrefutável"35.

Para Justino, nenhum pensador antigo possuiu integralmente o Verbo. O que nos prova isso é o fato de que eles discordavam uns dos outros, pois cada um falou de acordo com a parcela do Verbo contida em si.

30 Cf. BOEHNER; GILSON, 2012, p. 29.

31 JUSTINO, Apologia II, 10,2. In. Patrística 3, p. 70-71.

32 BOEHNER; GILSON, 2012, p. 29.

33 Ibid. 13,4. In. Patrística 3, p. 73.

34 Cf. BOEHNER; GILSON, 2012, p. 29.

35 JUSTINO, Apologia II, 13,3. In. Patrística 3, p. 73. 
Esse Logos parcial Justino chama de "germe" ou semente de logos, que, assim como afirmavam os estóicos, está presente em todos os homens ${ }^{36}$. Dizia que, assim como a semente poderia germinar e dar frutos, o germe do logos poderia levar os pagãos ao logos integral manifestado em Cristo.

Para Justino, todos os homens possuem esse germe, essa semente do Verbo. "Como a semente está para o fruto maduro, assim o germe do Logos dado aos pagãos está para o Logos integral manifestado em Cristo" ${ }^{37}$. Como os antigos filósofos e escritores possuíam somente esse Logos germinal, fica lógico a conclusão de que a acessibilidade deles à verdade só se concretizava conforme a capacidade mental dos mesmos, de onde vinham as diversas doutrinas que muitas vezes eram contraditórias, mas possuíam, no fundo, certas verdades, vindas do germe do Logos existente em $\mathrm{si}^{38}$.

\section{O surgimento de uma Filosofia Cristã da história e de um Humanismo Cristão}

A afirmação de que Jesus Cristo é o Logos e de que os filósofos antigos, anteriores a Cristo, participaram desse Logos, levou Justino a traçar o primeiro esboço de uma filosofia cristã da história e os fundamentos de um humanismo cristão ${ }^{39}$.

São Justino afirmou que o Logos é e sempre foi odiado pelo mal. E isso é uma herança certa para os homens que participam do logos e fogem dos vícios ${ }^{40}$. Essa foi a causa da morte de filósofos como Heráclito e Sócrates, por exemplo. Essa herança atingiu seu auge na perseguição aos cristãos que já participavam do Logos total, em Cristo Jesus ${ }^{41}$.

Segundo ele, "com o propósito de impedir a vitória do Logos, os demônios inventaram a mitologia pagã e propalaram as lendas mais fantásticas, para que os milagres de Cristo fossem acolhidos com o mesmo ceticismo que tiveram de enfrentar as fábulas dos poetas" ${ }^{\prime \prime 2}$. Assim, incutiram a perseguição contra a doutrina de Cristo, assim como já faziam com as verdades dos antigos filósofos que, muitas vezes, por amor e em defesa do Logos, da verdade, se colocaram contrários até mesmo à mitologia pagã43.

Assim, os antigos filósofos, participaram não só do mesmo Logos, mas também do mesmo destino doloroso dos cristãos. Por isso, podemos chamá-los de "cristãos antes de Cristo"44. "A comunidade cristã, formada pela participação, quer parcial, quer total, no mesmo Logos, existiu, pois, em todo curso da história”45. Dessa forma, podemos dizer que a história da filosofia estará na história do cristianismo.

36 Cf. Idib. 13. Patrística 3, p. 73.

37 BOEHNER; GILSON, 2012, p. 30.

38 Cf. Ibidem.

39 Cf. Ibidem.

40 "Com efeito, como já anotamos, os demônios sempre se empenharam em tornar odiosos aqueles que, de algum modo, quiseram viver conforme o Verbo e fugir da maldade" (JUSTINO, Apologia II, 7,2. In. Patrística 3, p. 69.)

41 "Portanto, não é de se admirar se eles, desmascarados, procuram também tornar odiosos, e com mais empenho ainda, àqueles que vivem não apenas de acordo com uma parte do Verbo seminal, mas conforme o conhecimento e contemplação do Verbo total, que é Cristo" (JUSTINO, Apologia II, 7,3. In. Patrística 3, p. 69.)

42 BOEHNER; GILSON, 2012, p. 30.

43 Cf. JUSTINO, Apologia I, 54. In. Patrística 3, p. 51-52.

44 Cf. ibid. 46. In. Patrística 3, p. 46-47.

45 BOEHNER; GILSON, 2012, p. 30. 
Aqui, podemos já perceber os primeiros sinais do surgimento de uma filosofia da história, "os quais irão desdobrar-se numa visão universal da história na Civitas Dei de Santo Agostinho"46.

Da mesma forma, temos o surgimento de um certo humanismo no interior do cristianismo. Todo o mal e todo o bem que se praticou, foi feito em vista do Logos. Todo bem provém de Cristo, o Verbo encarnado, a verdade de Deus. Assim, todo bem praticado pertence aos cristãos, herdeiros do Verbo ${ }^{47}$.

"Em Justino, o cristianismo reivindica para si, pela vez primeira, o direito de herança à cultura antiga, senão em toda a sua extensão, pelo menos no que respeita aos seus valores mais elevados". Por isso, podemos ver muitos séculos depois, na fundamentação do humanismo cristão, bases retiradas de comentários sobre as afirmações do próprio Justino.

Assim, podemos afirmar que Justino, filósofo e mártir cristão, trouxe à filosofia cristã, bases para fundamentar tanto a filosofia da história realizada no seio do cristianismo, como o humanismo cristão, que tanto produziu no tempos posteriores.

\section{CONSIDERAÇÕES FINAIS}

Ao término de nosso estudo, podemos ver que, muitos problemas e questionamentos que nos deparamos, já foram trabalhados por pensadores importantes anteriormente na história. Justino teve que resolver o problema da justificação da filosofia, em relação à sua ligação possível com o cristianismo, em especial da ligação que há entre a revelação de Deus, como a verdade plena, e as verdades que aparecem nas afirmações dos filósofos e escritores anteriores a Cristo.

Disso, podemos tirar luzes para compreendermos a necessidade que há no estudo filosófico antes de adentrarmos na busca de aprofundamento teológico. Há uma ligação intrínseca entre esses dois saberes. A filosofia se mostra como predecessora da doutrina cristã como uma busca, mais primitiva, pela verdade plena, ao passo que a doutrina cristã se dá como a culminância da revelação dessa verdade na encarnação do Verbo divino. Por isso, o filósofo chega a denominar o cristianismo como a "verdadeira filosofia".

No entendimento de Justino, os filósofos anteriores a Cristo já comungavam, mesmo que de forma primitiva e não plena, da verdade revelada nEle. Nas buscas que empreenderam pelo conhecimento daquilo que é eterno e inquestionável no mundo, nas vidas éticas e morais que praticaram, mostraram que em si já possuíam "sementes do verbo". Neles a verdade plena de Deus já se manifestava, porém, de forma parcial. Por isso, Justino chega a chamá-los de "cristãos antes de Cristo".

A verdade plena, o Logos de Deus, se revela em Cristo, o Verbo encarnado. Assim, a doutrina cristã se mostra como a culminância da filosofia antiga. A finalização plena da busca pela verdade empreendida pelos antigos.

Filosofia e cristianismo se complementam de forma surpreendente. A primeira como precedência da segunda e essa como culminância da revelação do objeto buscado pela outra, a saber, o conhecimento da verdade plena do universo.

Aqui se resolve o impasse apresentado por nós inicialmente. A necessidade do estudo filosófico antes do teológico se dá, além do desenvolvimento da argumentação e do entendimento de termos 46 Cf. Ibidem.

47 Cf. JUSTINO, Apologia II, 13,4. In. Patrística 3, p. 73. 
usados em ambos os saberes, pelo fato de ser necessário estudar antes o que precede a verdade, toda preparação e caminho da humanidade em busca dessa, e a culminância dessa busca na revelação do logos, a verdade de Deus, encarnada em Cristo Jesus.

Antes de adentrarmos no entendimento da revelação da verdade, devemos compreender todo trajeto feito pela humanidade em direção a essa. E, de que forma Deus, através de seu filho Jesus, revela essa verdade que, de alguma forma, já estava presente no coração e no entendimento dos pensadores antigos.

Além disso, percebemos como a filosofia de Justino trouxe as bases para o desenvolvimento de duas importantes áreas no estudo teológico. Com suas afirmações, no decorrer dos tempos, o cristianismo pode formar em seu seio um estudo mais profundo da história, levando em conta o desenrolar do pensamento humano anterior e posterior a Cristo. Como vimos, é de Justino que se tirou as bases para o desenvolvimento de uma filosofia da história no cristianismo e, além disso, de um humanismo cristão, tão trabalhado nos anos posteriores.

Assim, concluímos que, com sucesso, conseguimos achar algumas luzes para a compreensão da ligação que há entre filosofia e teologia. Com isso, se entende também o porquê da necessidade do aprofundamento filosófico antes do teológico. Resumindo, afirmamos que, antes de conhecer a verdade plena, o Logos de Deus, o conteúdo da revelação dada em Cristo, é importante compreendermos o modo como essa verdade já estava presente na humanidade, sendo manifestada, de forma primitiva, já nos escritos e nas defesas dos pensadores antigos. É necessária a compreensão da filosofia antes da teologia porquê, segundo Justino, a Filosofia foi e é o caminho para a contemplação da verdade plena revelada por Deus, em Cristo.

\section{REFERÊNCIAS}

BOEHNER, Philotheus; GILSON, Etienne. História da filosofia cristã: desde as origens até Nicolau de usa. Tradução de Raimundo Vier, O. F. M. 13. ed. Petrópolis: Vozes, 2012.

BOGAZ, Antônio S.; COUTO, Márcio A.; HANSEN, João Henrique . Patrística: caminhos da tradição cristã : textos, contextos e espiritualidade da tradição dos padres da Igreja antiga, nos caminhos de Jesus de Nazaré. São Paulo: Paulus, 2008

CABRAL, Géster de Sousa. A Plenitude do logos: o cristianismo como cumprimento de um projeto filosófico, segundo Justino de Roma. Monografia (licenciatura plena em Filosofia). Belo Horizonte: Instituto Santo Tomás de Aquino, 2013.

DI BERARDINO, Angelo. Dicionário Patrístico e de Antiguidades cristãs. São Paulo: Paulus, 2002.

DI BERARDINO, Angelo; FEDALTO, Giorgio; SIMONETTI, Manlio. Dicionário de literatura patrística. 1. ed. São Paulo: Ave Maria, 2010.

FARRÉ, Luiz. Filosofia cristiana, patrística y medieval. Buenos Aires: Nova, 1960.

FIGUEIREDO, Dom Fernando Antônio. Introdução à Patrística: vida, obras e doutrina cristã nos primeiros anos da Igreja. Petrópolis: Vozes, 2009. 
FIGUEIREDO, Fernando Antônio, O.F.M. Curso de teologia patrística I: a vida da Igreja primitiva (séculos I e II). 2. ed. Petrópolis: Vozes, 1986.

GILSON, Etienne. A Filosofia na Idade Média. Tradução Eduardo Brandão. São Paulo: Martins Fontes, 1995. HAMMAN, A. Os Padres da Igreja. 2. ed. São Paulo: Paulinas, 1985.

HANSEN, João H.; BOGAZ, Antônio S.; COUTO, Márcio A. Patrística caminhos da tradição cristã: textos, contextos e espiritualidade da tradição dos padres da Igreja antiga, nos caminhos de Jesus de Nazaré. São Paulo: Paulus, 2008.

JAPIASSU, Hilton; MARCONDES, Danilo. Dicionário Básico de Filosofia. Rio de Janeiro: Jorge Zahar Editor, 1990.

JOÃO PAULO II. Carta encíclica "fides et ratio": sobre as relações entre fé e razão. 2. ed. São Paulo: Paulus, 1998. (Série Magistério da Igreja)

JUSTINO DE ROMA. I e II Apologias; Diálogo com Trifão. Tradução de Ivo Storniolo e Euclides M. Balancin. 2. ed. São Paulo: Paulus, 2014. Coleção Patrística Vol.3

MANZANARES, César Vidal. Dicionário de patrística. 2. ed. Aparecida: Santuário, 1995.

MORESCHINI, Claudio. História da filosofia patrística. São Paulo: Loyola, 2008.

OSBORNE, Eric F. Justin Martyr. Tubingen: BHT Gerhard Ebeling, 1973.

PADOVESE, Luigi. Introdução à teologia patrística. São Paulo: Loyola, 1999.

QUASTEN, J. Patrologia I: hasta el concilio de Nicea. Madrid: Biblioteca de Autores Cristianos (BAC), 2004.

SÁNCHEZ, Sylvain J. G. Problemes historiques du Dialogue avec Triphon de Justin Martyr. Revista Augustiniana, v. XLII, n 128. p. 653-714. Mayo/Ago. 2001.

STOCKMEIER, Peter. Fede e religione nella Chiesa primitiva. Brescia: Paideia, 1976.

WITTER, Hans-Jörg. Logos Spermatikos. A enculturação do Cristianismo no mundo grecoromano e a sua relação com outras tradições religiosas segundo Justino. Dissertação (Mestrado) - Pontifícia Faculdade de Teologia Nossa Senhora da Assunção. São Paulo, 1998. 
